\title{
Main elements for pig price forecasting
}

\author{
A. VIGNE, M. RIEU \\ I.T.P., Service Economie, 34, boulevard de la Gare, 31500 Toulouse
}

The highly fluctuating variation of pig prices results from several components which should be identified and examined separately. First for making a relevant evaluation of the observed fluctuations, but also with the aim of forecasting it.

The major hypothesis is that one or several explanatory factors correspond to each component, i.e., season, cycle market trend and accidents.

These explanatory factors, mainly E.E.C. pig production volume and pig feed price, can be identified through the analysis of the past results.

Forecasting consists in modelizing each component of pig price from predictions based on its determining elements. An example of forecasting is given in 1984 which shows the relevance of the model.

\section{PORGEP : a decision aid for short-term management forecasting in pig production}

\author{
O. TEFFENE, Y. SALAÜN, M. QUERNE \\ I.T.P., Service Economie, B.P. 3, 35650 Le Rheu
}

A model for short-term management forecasting $\left({ }^{1}\right)$ in pig production (PORGEP) was developed by I.T.P. with the aim of providing specialists and farmers with an operational aid based on the economic analysis and enabling :

- the determination of production objectives in specifying the passage from the existing situation to the objective;

- technical and economic forecasting of turn-over, flux and stocks of animals during pregnancy, post-weaning and fattening, feed intake at the different stages, the main elements of the treasury and of economic results;

- a permanent control of production from simple indicators, with a presentation per period of time (weeks) and cumulative so as to analyse the observed discrepancies.

The components of the model, their interactions and the operating rules of the system are described. The utilization of this model by farmers and the exploitation of the results are discussed.

This model involving the use of microcomputers on the farm completes the existing management programmes (technical, economic,...) which have already a marked effect on the French pig production : after experimentation, it will be integrated in the management system of pig herds.

(1) A long-term simulation model, PORSIM, intended for analysis of investments was presented at the French swine research days of 1983, pp. 129-148. 